\title{
Announcement: Increased Length Limit for Rapid Communications in Physical Review E
}

Rapid Communications in the Physical Review are intended for the accelerated publication of important new results and are thus given priority in editorial processing and production. Starting January 1, 2015, the length limit for Rapid Communications in Physical Review E will be increased from 3500 words (or approximately 4 pages) to 4500 words (or approximately 5 pages). As before, the word count does not include the title, byline, abstract, or references. The Physical Review E editors are confident that this change makes it easier for authors to publish self-contained articles, and that inclusion of additional material in the article benefits the journal readership.

Published 17 December 2014

DOI: 10.1103/PhysRevE.90.060001

PACS number(s): $01.10 . \mathrm{Cr}$ 